\title{
Conditioned fear and neophobia following inescapable shock
}

\author{
THOMAS R. MINOR \\ University of California, Los Angeles, California
}

\begin{abstract}
Lick-suppression tests were used in seven experiments to assess the transsituational transfer of fear in the learned helplessness paradigm. Two sources of fear combined to suppress test drinking in inescapably shocked rats. A situational odor was strongly associated with shock pretreatments and mediated the transfer of conditioned fear during testing. Fear of the pretreatment odor was greater following inescapable shock than after escapable shock or restraint. This conditioned suppression was retained for at least $72 \mathrm{~h}$ after pretreatment. Neophobia was enhanced as a second, nonassociative reaction to inescapable shock. Unconditioned fear was augmented by a novel odor in the test context, but otherwise was weak and dissipated within $72 \mathrm{~h}$. However, neophobia was necessary for differential conditioned suppression in inescapably shocked rats. The pretreatment odor elicited fear only when tested in a novel context. Initial habituation to the test apparatus reduced conditioned fear. These data provide additional evidence for odor-mediated transfer of helplessness. Conditioned fear and neophobia are discussed in relation to recent anxiety interpretations of the phenomenon.
\end{abstract}

Prolonged exposure to inescapable and unavoidable electric shock impairs later escape performance in several species, whereas comparable experience with escapable or avoidable shock usually does not (Maier \& Seligman, 1976). Early interpretations of this helplessness effect emphasized the acquisition of cognition (Seligman \& Maier, 1967) or behavior (Anderson, Crowell, Cunningham, \& Lupo, 1979; Bracewell \& Black, 1974; Glazer \& Weiss, 1976) during exposure to inescapable shock that emerged during later testing to interfere with escape performance. More recent hypotheses, however, attribute the differential effects of escapable and inescapable shock to their anxietyprovoking characteristics (e.g., Gray, 1982; Mineka, Cook, \& Miller, 1984; Minor, Dess, \& Overmier, in press; Minor \& LoLordo, 1984; Weiss et al., 1982; Weiss et al., 1981).

Anxiety interpretations are based on the premise that inescapable shock is more fear-inducing than is escapable shock (e.g., Mowrer \& Viek, 1948). Recent elaborations of this view argue that heightened fear during inescapable shock has two immediate consequences: (1) fear is conditioned to apparatus cues and (2) chronic, intense activation of the neural pathways subserving anxiety results in an imbalance among critical neurotransmitters (cf. Weiss et al., 1982; Weiss et al., 1981). These associative and nonassociative factors interact to influence later test performance. Although the nonassociative deficit eventually dissipates, subjects remain vulnerable to sub-

The author wishes to thank K. L. Hadskis, M. Albright, and Y. Furman for assistance in conducting this research, which was supported by grants from the University of California Senate and the National Institute of Mental Health (MH41170-01). Reprint requests may be addressed to the author, Department of Psychology, 405 Hilgard Ave., UCLA, Los Angeles, CA 90024-1563. sequent stresses for 48-72 $\mathrm{h}$. The conditioning of apparatus cues presumably is more permanent. Fear elicited by similar cues during testing reactivates fear-related pathways. If testing occurs shortly after pretreatment, neural impairment is reinstated and performance deficits ensue. Escapable shock does not impair test performance because it elicits less fear. Neural pathways are not overly taxed as a result, and less fear is conditioned to apparatus cues.

Although this type of hypothesis has the potential to integrate a large number of observations concerning helplessness, several basic assumptions have yet to be tested. Indeed, evidence that fear varies with stressor controllability remains equivocal. Stimuli predicting controllable and uncontrollable aversive events have been found to be differentially fear-inducing in some studies (Brennan \& Riccio, 1975; Desiderato \& Newman, 1971; Mineka et al., 1984; Mowrer \& Viek, 1948; Osborne, Mattingly, Redmon, \& Osborne, 1975), but not others (Brimer \& Kamin, 1963; Morris, 1974; Payne, 1972; Randich \& LoLordo, 1979; Weisman \& Litner, 1972). In the most extensive of these studies, Mineka et al. (1984) used multiple measures of fear to demonstrate that greater fear is associated with stimuli in the original pretreatment apparatus following inescapable shock than following escapable shock. However, an important aspect of helplessness is the broad transfer of impairment across situations. Whether differences in fear actually transfer to a different apparatus is unclear. Although brief stimuli paired with escapable and inescapable shock in one context have been shown to differentially suppress behavior in another (Brennan \& Riccio, 1975; Desiderato \& Newman, 1971), a discrete signal is not necessary for helplessness effects to transfer broadly; in fact, the presence of such cues during pretreatment can eliminate the otherwise deleterious effects of inescapable 
shock on test performance (Jackson \& Minor, 1988). Thus, there is no compelling evidence that fear conditioned during pretreatment is transferred to the test phase to disrupt performance, as the anxiety hypothesis assumes.

Minor and LoLordo (1984) reported that similar stress odors in the pretreatment and test apparatus provide a basis for stimulus generalization of the effects of inescapable shock to a variety of test tasks in rats. These odors tend to overshadow other features of a conditioning context, leading to a strong odor-shock association (King, 1969). As a result, odor becomes a critical retrieval cue in later tests of aversive learning. In a helplessness experiment, similar odors must be present in both experimental phases for impaired escape latencies (Minor \& LoLordo, 1984), defensive behavior (Williams, 1987), and long-term hypoalgesia to occur $24 \mathrm{~h}$ after pretreatment (Coen, 1985). When odors are mismatched, inescapably shocked rats perform as well as restrained controls. This pattern is obtained regardless of whether the pretreatment odor is biological (stress odorants) or artificial.

The following experiments utilized the finding that helplessness effects can be conditioned to an artificial odor in order to examine the transfer of fear following inescapable shock. The basic procedure consisted of exposing thirsty rats to shock pretreatments in the presence of a distinct odor. Rats were later given the opportunity to drink in a different chamber in which the pretreatment odor either was or was not present as a static cue. The suppression of drinking in the presence of the odor was taken as a measure of conditioned fear. Thus, these experiments provided the first direct test of the fear-inducing properties of a stimulus dimension that contributed importantly to the transsituational transfer of helplessness.

\section{EXPERIMENTS 1A AND 1B}

These experiments were designed to identify a set of conditions under which an odor associated with inescapable shock differentially suppressed drinking in thirsty rats. The only difference between the two experiments was the extent to which the test context was familiar to the subjects at the time of testing. Water-deprived rats were given access to water on each of 5 consecutive days either in the testing chambers (Experiment 1A) or in their home cages (Experiment 1B). The rats were exposed to inescapable tailshocks or simple restraint immediately after the drinking session on Day 5. Peppermint odor was presented throughout the pretreatment session for all rats. Equal numbers of rats from each stress condition were then given the opportunity to drink in the test chambers in either the presence or the absence of the pretreatment odor. The suppression of drinking in the presence of the odor was taken as an index of conditioned fear.

\section{Method}

Subjects. Thirty-two experimentally naive male albino rats (Charles River, Wilmington, MA), weighing 290-334 g, were housed in individual cages with free access to food and water in a colony room maintained on a 12:12-h day: night cycle in each of the two experiments. The rats were given 1 week to acclimate to the housing conditions before the experimental treatments began, which were conducted during the light portion of the day/night cycle.

Apparatus. Pretreatment occurred in four Plexiglas restraining tubes, $23 \mathrm{~cm}$ in length and $6 \mathrm{~cm}$ in diameter. Adjustable front walls prevented the rats from moving forward in the tubes. A rat's tail extended through the rear door of the tube and was taped to a plastic rod. Unscrambled shock was delivered from one of four GrasonStadler (Series 700) shock generators to electrodes attached to the rat's tail with electrode paste and tape. Odors were presented in the restraining tubes by soaking gauze pads located behind the perforated front wall with peppermint extract. Common garden hose $(1.2 \mathrm{~cm}$ in diameter) was attached to each of two vacuum fittings located $1.5 \mathrm{~cm}$ from the end of the tube and $4 \mathrm{~cm}$ to either side of the top center line. The hose was connected to the manifold of a vacuum cleaner. The $120-\mathrm{V}$ ac vacuum motor was operated at $85 \mathrm{~V}$ ac. This arrangement created an airflow from the front to the rear of the tube, thus allowing continuous presentation of the experimental odor and eliminating urine and feces odors from the tube and room. Each restraining tube was housed in an illuminated, sound-attenuating chest containing an exhaust fan that masked extraneous noises

Lick-suppression tests were conducted in two $(30 \times 21 \times 24 \mathrm{~cm})$ chambers. A circular aperture $(5 \mathrm{~cm}$ in diameter) in one of the aluminum end walls provided access to a water spout. The water spout was located $3 \mathrm{~cm}$ behind the aperture in a white Plexiglas box attached to the outer wall of the chamber. The drinking box $(3 \times 12 \times 13 \mathrm{~cm})$ was continuously illuminated by a 6 -W lamp. Odors were presented by applying peppermint extract to gauze sponges located beneath wire screening on the floor of the drinking box. Contacts with the water spout (licks) were recorded by lickometers (BRS-LVE, Model 101) when a circuit was completed with the grounded grid floor of the chamber. The chambers were located in a dark, quiet room that was physically distant from the room in which pretreatment had occurred.

Unless specified otherwise, the pretreatment and testing apparatus was thoroughly cleaned in all experiments to remove the potentially confounding effects of extraneous odors before each rat received experimental treatments. Residual peppermint odor was removed with alcohol. The entire apparatus was then cleaned in a solution of hot water and Control, an industrial deodorizing and disinfectant cleaner. Finally, each chamber was washed in a sodium hydroxide solution and rinsed with water.

Procedure. In Experiments $1 \mathrm{~A}$ and $1 \mathrm{~B}$, the rats were assigned to one of four groups on the basis of weight. Four rats were selected that differed in body weight by no more than $7 \mathrm{~g}$ and were assigned to groups. The next 4 rats were matched for weight and assigned to groups so as to minimize differences in group mean weights. The process was continued until there were 8 rats in each group. In the present and following experiments, group mean weights differed by no more than $6.3 \mathrm{~g}$.

Water bottles were removed from the rats' home cages. Access to water was restricted to a 30 -min session on each of the next 5 days. These sessions occurred in lick-suppression chambers in Experiment $1 \mathrm{~A}$; in Experiment $1 \mathrm{~B}$, water was available in the home cages. Thus, the only difference between the experiments was that the drinking chambers were familiar at the time of testing in Experiment $1 \mathrm{~A}$ but were novel in Experiment 1B.

Two groups were exposed to 805 -sec inescapable tailshocks in restraining tubes immediately after the drinking session on Day 5. Shock trials were presented on a variable-time 60 -sec schedule (range: $20-230 \mathrm{sec}$ ). Shock intensity was $1.0 \mathrm{~mA}$. Two additional groups were restrained in tubes for the same time period and received no shocks. Restraining tubes were odorized by peppermint extract $(0.3 \mathrm{ml})$ for all groups approximately $30 \mathrm{sec}$ before the start of the session. The peppermint odor was replenished after every 20 shocks 
or a comparable arnount of time for restrained rats. All rats received an additional 15-min access to water in their home cages immediately after pretreatment.

Lick-suppression tests were conducted 22 and $48 \mathrm{~h}$ later. The rats were placed in the drinking chambers and received $30-\mathrm{min}$ access to water in each session. The pretreatment odor was present during testing for one shocked (IO) and one restrained (RO) group: $0.3 \mathrm{ml}$ of peppermint extract was applied to gauze pads on the floor of the Plexiglas drinking box $5 \mathrm{~min}$ before a rat entered the chamber. No odor was presented to the remaining shocked (INO) and restrained (RNO) rats. Total licks at the water spout were recorded for each session. In addition, the number of licks occurring in the first 15 min of each session was recorded in 5-min blocks as a more sensitive measure of group differences. All rats received an additional 30-min access to water in their home cages immediately after the first test session to compensate for differential drinking during the session.

\section{Results}

Experiment 1A. Lick rates in the drinking chambers increased over the initial four baseline sessions in all groups, but were stable on Sessions 4 and 5 and were equivalent between groups $(F \mathrm{~s}<1.01)$. Figure la shows drinking by each group during the two lick-suppression tests. Average lick rates based on the entire session are shown in the upper portion of the figure. The pretreatment odor generally suppressed drinking in both test sessions, but did not differentially influence performance in the shocked (IO) and restrained (RO) groups. Evidence of a disruptive effect of preexposure to inescapable shock also was absent in the no-odor groups (INO and RNO). A mixed-design analysis of variance (ANOVA: group $x$ test day) yielded a significant main effect of group $[F(3,28)=6.73, p<.002]$. Neither the main effect of test day nor the group $\times$ test day interaction were statistically significant. Newman-Keuls comparisons $(\alpha=.05)$ indicated that the groups tested in the presence of the pretreatment odor drank significantly less than the groups tested in its absence. There were no significant differences between the shocked and restrained groups within each odor condition.

Drinking during the first 15 min of each test session is presented in blocks of $5 \mathrm{~min}$ in the lower portion of Figure 1a. These local drinking patterns also failed to dis-
12. FAMILIAR CONTEXT

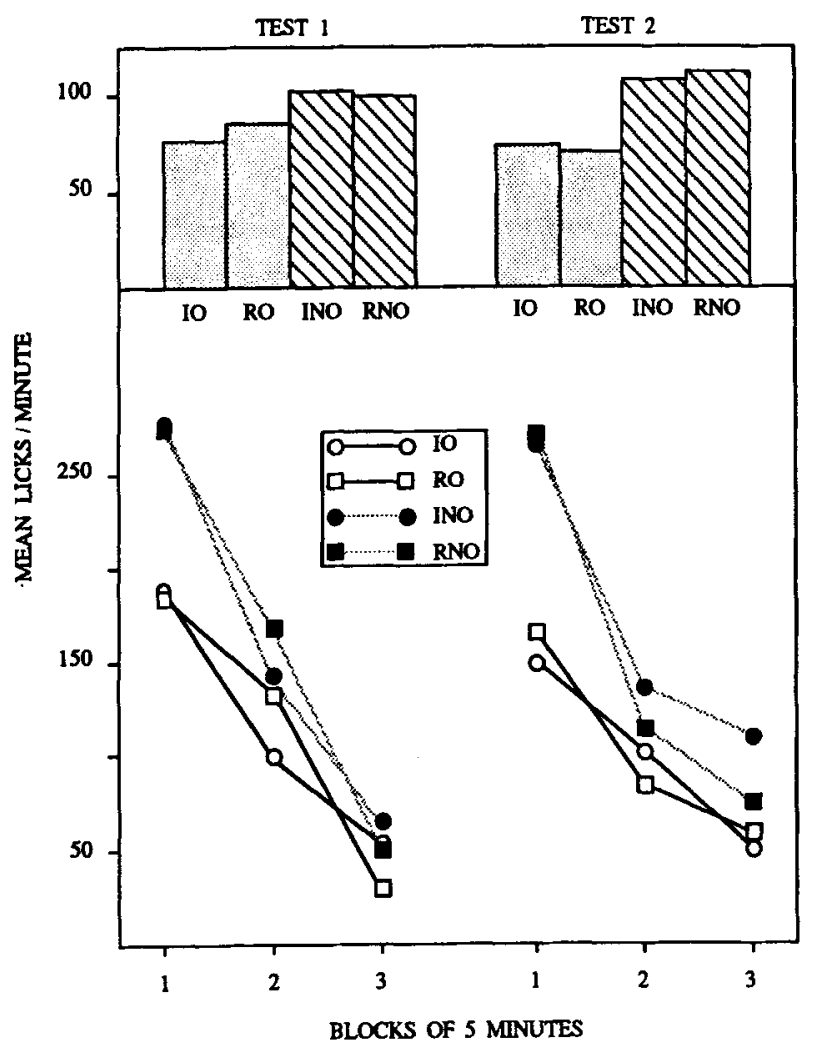

1b. NOVEL CONTEXT

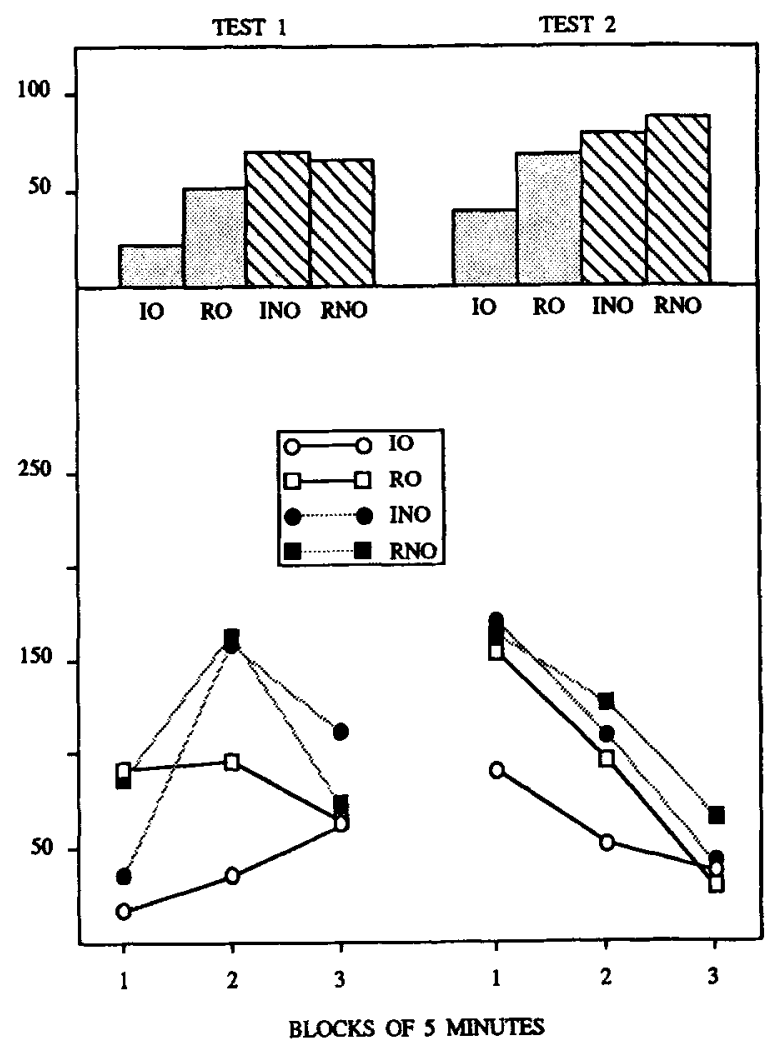

Figure 1. (a) Mean overall lick rates based on the entire $\mathbf{3 0}$ min of each test session (upper panel), and local lick rates during the first $15 \mathrm{~min}$ of each test session (lower panel) in 5 -min blocks. Thirsty rats were allowed to drink in the test chambers for five consecutive sessions prior to exposure to inescapable shock (I) or restraint (R) in the presence of peppermint odor in a different apparatus. All rats were given 30-min access to water in the test chambers 22 and $48 \mathrm{~h}$ later in either the presence (Groups IO and RO) or the absence (Groups INO and RNO) of the pretreatment odor. (b) Mean overall lick rates (upper panel) and local rates (lower panel) during the first three 5-min blocks of each test session in a novel drinking chamber. Thirsty rats were exposed to inescapable shock (I) or restraint (R) in tubes odorized by peppermint during pretreatment. Lick-suppression tests were conducted in a novel chamber 22 and $48 \mathrm{~h}$ later in either the presence (Groups 10 and RO) or the absence (Groups INO and RNO) of the pretreatment odor. 
tinguish between shocked and restrained rats. The pretreatment odor suppressed drinking in Groups IO and RO relative to their no-odor counterparts (Groups INO and RNO) during the first 5 min of each test session. Local drinking patterns were analyzed by computing separate mixed-design ANOVAs (group $\times$ time block) for each test session. Both ANOVAs yielded significant main effects of group $\left[F_{\mathrm{S}}(3,28)>4.60, p<.01\right]$ and time block $[F \mathrm{~s}(2,56)>21.86, p \mathrm{~s}<.001]$, and a significant group $x$ time block interaction $[F \mathrm{~s}(6,56)>3.41, p s<.004]$. In the present and following experiments, the locus of a group $\times$ time block interaction was analyzed by computing Newman-Keuls comparisons ( $\alpha=.01)$ of group means for each time block. These comparisons indicated that Groups INO and RNO, which did not differ from one another, drank significantly more than Groups IO and RO during the first $5 \mathrm{~min}$ of each test session. Groups $\mathrm{IO}$ and RO did not differ in drinking at these times. No other comparisons were statistically significant.

Experiment 1B. As shown in Figure 1b, the pretreatment odor differentially suppressed overall lick rates (upper panel) in inescapably shocked rats (Group IO) relative to restrained controls (Group RO) when testing occurred in a novel context. By contrast, overall drinking was equivalent among shocked (INO) and restrained (RNO) rats when the pretreatment odor was absent during testing. A mixed-design ANOVA (group $\times$ test day) yielded significant main effects of group $[F(3,28)=15.21$, $p<.001]$ and test day $[F(1,28)=5.89, p<.03]$. Because there was no interaction between variables, NewmanKeuls analyses of group differences were based on the pooled mean for both test sessions for each group. Groups INO and RNO did not differ in overall drinking; however, both groups drank significantly more than Groups IO and RO. Most importantly, Group IO drank significantly less than did all other groups.

Drinking during the first 15 min of each test session is shown in the lower panel of Figure 1b in blocks of 5 min. A mixed-design ANOVA (group $\times$ time block) of local drinking patterns during Test 1 yielded significant main effects of group $[F(3,28)=8.96, p<.001]$ and time block $[F(2,56)=6.95, p<.002]$, and a significant group $\times$ time block interaction $[F(6,56)=3.19$, $p<.01]$. Newman-Keuls comparisons $(\alpha=.01)$ of group lick rates at each time block indicated that Group IO drank significantly less than Groups RO and RNO during the first 5 min of Test 1 . Group INO did not differ significantly from Group IO. However, although drinking increased in Group INO during the second 5-min block of the test, so that it was equivalent to that in Group RNO, drinking remained suppressed in Group IO relative to Groups RO, INO, and RNO. Group RO also showed suppressed drinking during Block 2 relative to Groups INO and RNO. Significant differences in drinking did not occur during Block 3 of Test 1 .

A mixed-design ANOVA (group $\times$ time block) on Test 2 drinking yielded significant main effects of group $[F(3,28)=5.74, p<.004]$ and time block $[F(2,56)=$
$32.88, p<.001]$. The interaction between variables was not statistically significant. Newman-Keuls analysis of group differences ( $\alpha=.05$ ) indicated that Group IO drank significantly less overall during the first $15 \mathrm{~min}$ of Test 2 than did Groups RO, RNO, and INO, which did not differ from one another.

\section{Discussion}

The results of Experiment IB indicate that an odor associated with inescapable shock is capable of differentially suppressing drinking when its fear-inducing qualities are assessed in a novel context. Reduced drinking by IO rats in this experiment cannot be attributed to a nonspecific, stress-induced reduction in thirst or an inability to make the licking response. Substantial and sustained lick suppression in shocked rats was specific to the pretreatment odor. In the absence of the odor, overall lick rates in shocked rats were equal to control levels, although INO rats were somewhat slower to initiate drinking than were restrained controls during the first minutes of Test 1 .

Rats tested in the absence of the pretreatment odor (Groups INO and RNO) showed an inverted V-shaped change in lick rates over the first $15 \mathrm{~min}$ of Test 1 in Experiment 1B (lower panel of Figure 1b). This pattern probably reflects the initial time required to explore the chamber and locate the water spout (Block 1), followed by increased drinking in the second 5 min of the session. Decreases in drinking during the third 5-min block presumably resulted from some satiation and a decreased motivation to drink. This change in the baseline drinking rate creates a problem for detecting general suppression of drinking due to the presence of the pretreatment odor, as well as conditioned suppression in IO rats at any given point in time. For instance, even though Groups RNO and IO had equivalent lick rates during the third 5-min block of Test 1 , it seems very likely that the relatively low rate in Group RNO reflects satiation, whereas the low rate in Group IO probably resulted from continued conditioned suppression to the pretreatment odor. This problem suggests that lick rates based on consumption over the entire session, a measure of cumulative drinking, are best suited for detecting conditioned effects of the pretreatment odor, and are used in the following experiments to assess associative transfer of fear. However, despite the baseline problem with local rates, the fact that Group INO showed some initial suppression during Test 1 suggests that local rates should be useful in detecting transient and potentially nonassociative effects of inescapable shock. Consequently, local rates are presented in experiments concerned with transient effects of inescapable shock on drinking.

A comparison of Experiments $1 \mathrm{~A}$ and $1 \mathrm{~B}$ suggests that the specifics of a test procedure may limit the expression of any conditioned properties of the pretreatment odor. Unlike Experiment 1B, the pretreatment odor failed to differentially influence the performance of shocked and restrained rats in Experiment $1 \mathrm{~A}$ (when the drinking chambers were familiar at the time of testing). Fortunately, of the two experiments, the procedure of Ex- 
periment 1B most closely resembles a standard helplessness experiment. The effects of inescapable shock usually are assessed in a novel environment (cf. Maier \& Seligman, 1976). Thus, even though the combined outcome of these experiments suggests that an odor associated with inescapable shock does not unconditionally suppress behavior in a transsituational test, the procedure of Experiment $1 \mathrm{~B}$ was effective in this regard and is relevant to the standard helplessness experiment.

The test procedures in these experiments differed in terms of the familiarity and motivational significance of the test context. Either variable might have been responsible for the absence of an effect in Experiment 1A. For instance, association of the test context with water availability during baseline sessions may have established behavior or appetitive motivation that competed with and masked any fear elicited by the pretreatment odor at the time of testing. Alternatively, the subjects may have learned that the drinking chambers were "safe" during baseline sessions, thereby counterconditioning any aversive properties of the pretreatment odor. The potential contribution of these variables to test performance is addressed in a later experiment.

\section{EXPERIMENT 2}

Experiment 2 was designed to examine the fear-eliciting properties of an odor associated with escapable shock, yoked inescapable shock, or simple restraint using the procedure of Experiment 1B. The shock parameters used in Experiment 2 reliably produce a variety of disorders that are characteristic of helplessness in rats (Dess, Chapman, \& Minor, 1988; Haracz, Minor, Wilkins, \& Zimmermann, 1988; Minor, Jackson, \& Maier, 1984; Minor \& LoLordo, 1984). If the ability to control shock reduces the level of fear conditioned to the pretreatment odor, then escapably shocked rats should show faster acquisition of drinking (less overall suppression) than do inescapably shocked rats when that odor is presented in a novel test context.

\section{Method}

Subjects. Forty-eight male albino rats, weighing 291-317 g, were obtained from Charles River Co. and housed as in Experiment 1.

Apparatus. Pretreatment occurred in three Plexiglas wheel-turn chambers measuring $14 \times 11.5 \times 17 \mathrm{~cm}$. Two circular pieces of Plexiglas, $10 \mathrm{~cm}$ in diameter, were connected with 12 (7-cm-long, $0.6-\mathrm{cm}$-diam) stainless steel rods to form a cylindrical wheel. The wheel entered the front wall $3.5 \mathrm{~cm}$ from the ceiling and protruded $2.5 \mathrm{~cm}$ into the chamber. A rat's tail extended through the rear door of the chamber and was taped to a plastic rod. Unscrambled shock from one of two Grason-Stadler (Series 700) shock generators was delivered to electrodes attached to the rat's tail with electrode paste and tape. Odors were delivered through an aperture in the ceiling of the chamber by forcing air over a gauze sponge soaked with peppermint extract. Odors were simultaneously removed through an aperture in the rear door, which was connected to the vacuum apparatus described in Experiment 1. Each wheel-turn chamber was housed in a sound-attenuating chest containing an exhaust fan that masked extraneous noises. Lick-suppression tests were conducted in the drinking chambers described above.
Procedure. The rats were assigned to one of six groups of 8 rats each on the basis of weight and were adapted to the schedule of restricted water access described in Experiment 1B.

Two groups were exposed to 80 unsignaled shock-escape trials on a variable-time 60 -sec schedule in the wheel-turn chambers immediately after the home-cage drinking session on Day 5. Shock intensity was $1.0 \mathrm{~mA}$. Wheel-turn responses were ineffective during the first $0.8 \mathrm{sec}$ of each trial. Thereafter, shock was terminated by a $360^{\circ}$ turn of the wheel or was terminated automatically if the response requirement was not met within $30 \mathrm{sec}$ of shock onset. Each rat in each of these escape (E) groups controlled the shock duration on each trial for a second, inescapably shocked (Y: yoked) rat in an additional group. Thus, the members of each $E-Y$ pair received the same number, pattern, intensity, and duration of shocks, but differed in the extent to which they could control shock termination. The two remaining groups were restrained $(R)$ in the wheelturn chambers for an equivalent time period and received no shocks. The peppermint odor was continuously delivered throughout the session for all groups. All rats received an additional $15-\mathrm{min}$ access to water in their home cages immediately after the stress session.

Lick-suppression tests were conducted 22 and $48 \mathrm{~h}$ later. All rats received 30 -min access to water in the drinking chambers in each session. Peppermint odor was present during testing for one group from each pretreatment condition (Groups EO, YO, and RO): $0.3 \mathrm{ml}$ of peppermint extract was applied to gauze pads covering the floor of the Plexiglas drinking box $5 \mathrm{~min}$ before each test. No odor was presented for the other groups in each pretreatment condition (Groups ENO, YNO, and RNO). All rats received an additional 30-min access to water in their home cages immediately after the first test session to compensate for differential drinking during the session.

\section{Results and Discussion}

All rats in Groups EO and ENO learned to turn the wheel to escape shock during pretreatment. Escape latencies decreased across blocks of 10 trials and were roughly equivalent in the two groups. A mixed-design ANOVA (group $\times$ trial block) yielded a significant main effect of trial block $[F(7,98)=5.32, p<.001]$; however, neither the main effect of group nor the group $\times$ trial block interaction was statistically significant. This finding indicates that Groups EO, YO, ENO, and YNO received statistically equal amounts of shock during pretreatment.

Mean lick rates based on the entire $30 \mathrm{~min}$ of each test session are shown in Figure 2 for each group. Groups tested in the absence of the pretreatment odor (ENO, YNO, and RNO) had similar ingestion rates on both test days. However, drinking varied with the escapability of pretreatment shocks when the test chamber was odorized by peppermint: drinking in Group RO was comparable to the no-odor groups, but lick rates in Group EO were slightly suppressed from this level. More importantly, lick rates were markedly lower in Group YO than in all other groups on both test days.

A mixed-design ANOVA (pretreatment $x$ test odor $x$ test day) yielded a significant main effect of test day $[F(1,42)=23.35, p<.001]$, indicating that drinking generally increased across sessions. The main effects of test odor $[F(1,42)=35.17, p<.001]$ and pretreatment $[F(2,42)=10.09, p<.001]$, and the pretreatment $\times$ test odor interaction $[F(2,42)=6.15, p<.005]$ also 


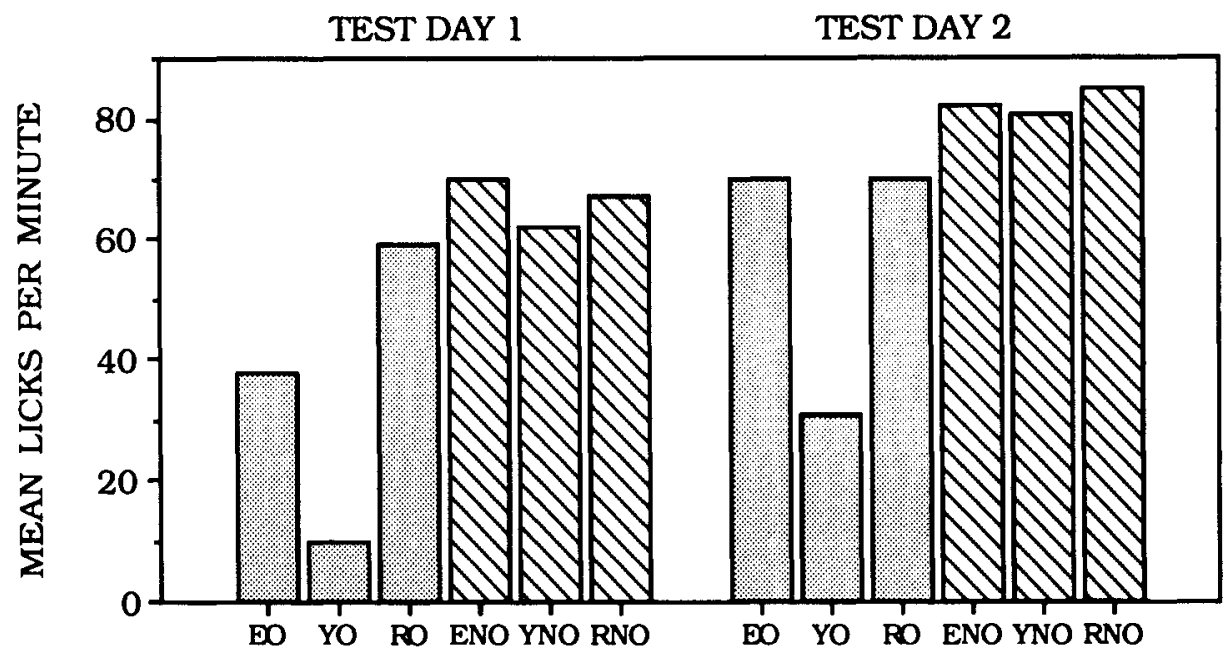

Figure 2. Mean lick rates in each of two 30-min test sessions for rats preexposed to escapable shock (E), yoked inescapable shock $(Y)$, or restraint $(R)$ in the presence of peppermint odor and tested for lick suppression in either the presence (Groups EO, YO, and RO) or the absence (Groups ENO, YNO, and RNO) of the pretreatment odor 22 h (Test Day 1) and 48 h (Test Day 2) later.

were statistically significant. Because no variable interacted with test day, Newman-Keuls contrasts $(\alpha=.05)$ were based on the pooled mean for both test sessions in each group. Drinking was significantly lower in Group YO than in all other groups, which did not differ from one another.

These data indicate that the ability of the pretreatment odor to suppress drinking in a transsituational test varies with the controllability of pretreatment shocks. Whereas the pretreatment odor moderately suppressed licking on the first test in escapably shocked rats, substantial suppression occurred in inescapably shocked rats on both test days. In the no-odor test conditions, overall lick rates were comparable among escape, yoked, and restrained ratsalthough inescapably shocked rats again showed a transient retardation of drinking in the initial minutes of Test 1 . This general outcome is consistent with the previous work suggesting that stimuli associated with inescapable shock are more anxiety-provoking than stimuli predicting equal amounts and durations of escapable shock (Desiderato \& Newman, 1971; Mineka et al., 1984; Mowrer \& Viek, 1948; Osborne et al., 1975).

This experiment also provides the first clear evidence that different levels of fear transfer to the test phase following preexposure to escapable and inescapable shock. Previous studies of associative transfer in the helplessness paradigm strongly suggest that similar odors must be present in the pretreatment and test apparatus for impaired test performance to occur (Coen, 1985; Minor \& LoLordo, 1984; Williams, 1987). When odors are mismatched across experimental phases, inescapably shocked rats perform as well as restrained controls. This outcome occurs regardless of whether the pretreatment odor is biological (i.e., stress-produced odorants) or artificial (e.g., peppermint). Thus, the present data suggest that inescap- ably shocked rats often begin testing more afraid than do escapably shocked rats and restrained controls.

\section{EXPERIMENT 3}

Although the previous experiment provides additional evidence that situational odors are central to the transfer of helplessness across physically different environments, this associative cue may not be responsible for all aspects of transfer. Most importantly, behavioral impairment usually recovers within $72 \mathrm{~h}$ after exposure to inescapable shock (Maier, Coon, McDaniel, Jackson, \& Grau, 1980; Seligman, Rosellini, \& Kozak, 1975). This timedependent variation suggests either that helplessness ef fects are partially mediated by a nonassociative process, or that the odor-shock association established during pretreatment is readily forgotten (see Minor \& LoLordo, 1984, for a thorough discussion).

Even though aversive associations are usually retained over intervals longer than $72 \mathrm{~h}$ (Hoffman, Fleshler, \& Jensen, 1963), forgetting could provide a simple explanation for poststress recovery from helplessness. Situational odors may not serve as effective retrieval cues for the memory of inescapable shock when a transsituational test is conducted $72 \mathrm{~h}$ poststress. If so, a 72 -h test would be functionally equivalent to a $24-h$ test in which the pretreatment odor was physically absent. As several recent studies indicate, performance deficits are attenuated or eliminated under the latter conditions (Coen, 1985; Minor \& LoLordo, 1984; Williams, 1987).

Experiment 3 was designed to examine the retention of an odor-shock association over the 72 -h poststress recovery interval using the procedure of Experiment 1B. Thirsty rats were exposed to either inescapable tailshocks or restraint in the presence of peppermint odor. Lick- 
suppression tests were administered either 22 or $72 \mathrm{~h}$ later to independent groups representing each pretreatment condition. Testing occurred in either the presence or the absence of the pretreatment odor. If forgetting contributes to poststress recovery from helplessness, then the pretreatment odor should be less effective in suppressing drinking $72 \mathrm{~h}$ after inescapable shock, relative to a 22 -h test.

\section{Method}

Subjects and Apparatus. Sixty-four male albino rats, weighing 293-342 g, were obtained from Charles River Co. and housed as in Experiment 1. The apparatus was the same as in Experiment 1.

Procedure. The rats were assigned to one of eight groups of 8 subjects each on the basis of weight and were adapted to the schedule of restricted water availability. Immediately after the home-cage drinking session on Day 5, four groups were exposed to $805-\mathrm{sec}$ inescapable tailshocks, and four groups were restrained in tubes as in Experiment 1B. Peppermint was the pretreatment odor for all groups. Each rat received an additional 15-min access to water in its home cage immediately after the session.

A 30-min lick-suppression test was administered to two groups from each pretreatment condition $22 \mathrm{~h}$ later. Peppermint odor was present during testing for one shocked (IO-22) and one restrained (RO-22) group; no odor was presented to the other inescapably shocked (INO-22) and restrained (RNO-22) rats.

The remaining two groups in each pretreatment condition received 30 -min access to water in their home cages on Days 6 and 7 of the experiment. A 30-min lick-suppression test was conducted on Day $8,72 \mathrm{~h}$ after pretreatment. The pretreatment odor was present during testing for one inescapably shocked (1O-72) and one restrained (RO-72) group, but was absent for the other shocked (INO-72) and restrained (RNO-72) rats.

\section{Results and Discussion}

The results of the 22- and 72-h drinking tests are shown in Figure 3. Overall lick rates in the groups tested $22 \mathrm{~h}$ after pretreatment replicated the findings of Experiments $1 \mathrm{~B}$ and 2 . Whereas the restrained rats tested in the presence of the pretreatment odor (Group RO-22) were comparable to the no-odor groups (RNO-22 and INO-22), the pretreatment odor substantially reduced drinking in inescapably shocked rats (Group IO-22). Somewhat higher lick rates were evident for all groups in the 72-h groups, perhaps reflecting greater cumulative water deprivation at the time of testing. Nonetheless, the pretreatment odor still resulted in considerable suppression of drinking in Group 10-72 relative to the restrained control group (RO-72), despite the longer retention interval.

An ANOVA for randomized factors (pretreatment $x$ test odor $\times$ test time) yielded significant main effects of pretreatment $[F(1,56)=28.96, p<.001]$, test odor $[F(1,56)=19.8, p<.001]$, and test time $[F(1,56)=$ $3.96, p<.05$ ]. The pretreatment $\times$ test odor interaction also was significant $[F(1,56)=9.76, p<.005]$. Newman-Keuls comparisons $(\alpha=.05)$ indicated that Groups IO-22 and IO-72 did not differ significantly in overall test drinking. However, both groups drank significantly less than all other groups. No other comparisons were statistically significant.

Overall lick rates in Groups IO-22 and IO-72 were converted to a percentage of drinking by the appropriate restrained control group (Groups RO-22 and RO-72, respectively) to provide a more sensitive test of any differences in lick suppression. Mean percentage of control drinking

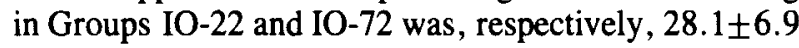
and 37.6 \pm 7.8 . Although this measure suggests that the pretreatment odor lost some of its ability to suppress drinking in inescapably shocked rats over the 72-h retention interval, the difference in means was not statistically significant $[t(14)=0.91, p>.05]$.

This experiment provides no evidence for forgetting as the principal mechanism for poststress recovery $72 \mathrm{~h}$ after exposure to inescapable shock. The pretreatment odor resulted in substantial suppression of drinking in inescapably shocked rats at this time, which was statistically equal

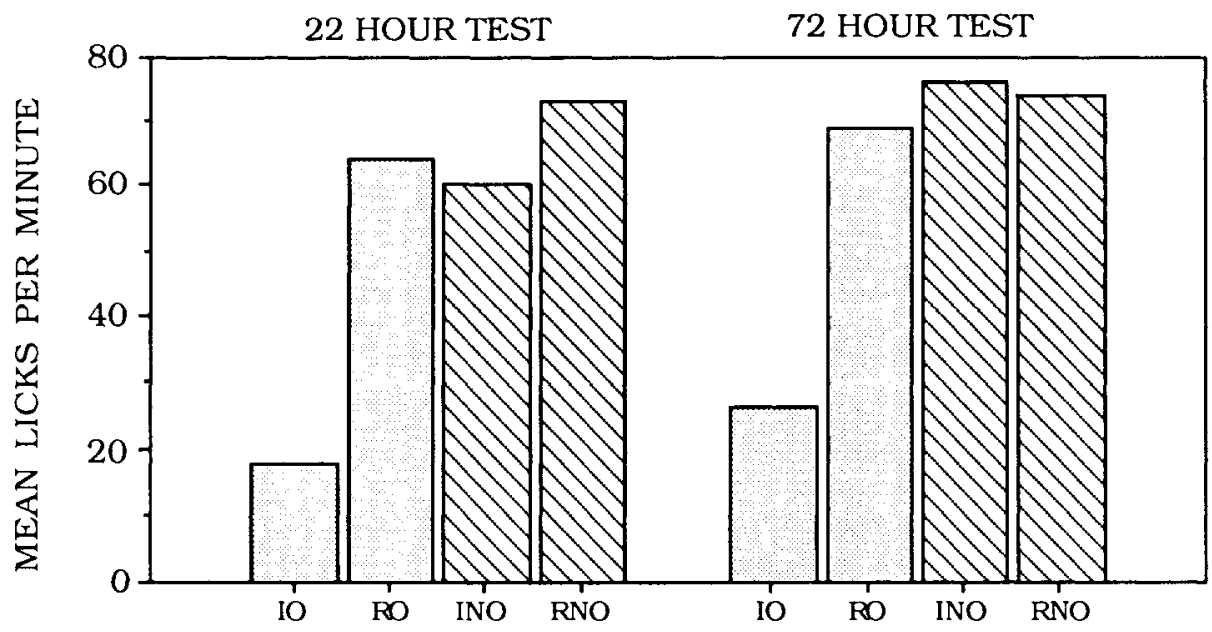

Figure 3. Mean lick rates based on a 30-min test session in groups preexposed to inescapable shock (I) or simple restraint $(R)$ in tubes odorized by peppermint extract and then tested for lick suppression in either the presence (Groups 10 and RO) or the absence (Groups INO and RNO) of the pretreatment odor. Testing occurred either 22 or $72 \mathrm{~h}$ after pretreatment for independent groups of rats. 
to the level seen in the 22-h test. Thus, the pretreatment odor appeared to be an effective retrieval cue for original learning, regardless of the retention interval.

Two considerations caution against drawing strong conclusions from the present data, however. First, even though overall lick rates were statistically equal in Groups IO-22 and IO-72, inescapably shocked rats did show slight recovery in the 72 -h test. Even a small diminution in the strength of the odor-shock association might produce a comparatively large improvement in escape performance or some other direct measure of helplessness. It should be recalled, however, that in standard tests for helplessness (e.g., shuttle-escape), rats typically are reexposed to shock. Any small loss in associative strength owing to a longer pretreatment-test interval should be reinstated by such shocks (cf. Spear, 1978).

A second and more serious limitation arises from the use of an artificial odor as the basis of transfer. Minor and LoLordo (1984) argued that, in a typical helplessness experiment, the stress odors of conspecifics occur as a common feature of pretreatment and test environments to provide the basis for associative transfer. Although both biological and artificial odors supported associative transfer in their experiments, these different odors may not have been equally associable with shock during pretreatment or equally memorable at the time of testing. At least some data suggest that the memory for stress odorants is remarkably complex in rodents-their effectiveness as retrieval cues may depend on whether odors present at the time of testing are appropriately aged for the retention interval (King, 1969; Thomas, Riccio, \& Myer, 1977). Unfortunately, there is enough uncertainty concerning the source of these biological odors, the way they are encoded and retrieved, and their potential role as pheromones (see Brown, 1979, for a review) to add considerable complexity to any generalizations from the present data. Thus, strong conclusions regarding the role of forgetting in the recovery from helplessness should await a direct test of the retention of an odor-shock association based on a biological odor.

\section{EXPERIMENT 4}

Certain findings from the previous experiments suggest that the level of fear experienced by inescapably shocked rats during testing was not solely determined by odor-mediated transfer. In Experiment 1B, inescapably shocked rats tested in the absence of the pretreatment odor (Group INO; lower panel of Figure 1b) were slow to initiate drinking relative to their restrained counterparts during Test 1 . This transient suppression was also evident in the no-odor test conditions of Experiments 2 and 3.

This transient effect of inescapable shock could have resulted from conditioning to cues other than the situational odor. For instance, although the pretreatment and test chambers were physically different in these experiments, transportation and handling cues were similar in both experimental phases. Such incidental stimuli may have been associated with inescapable shock pretreatment. Exposure to a similar regimen prior to testing might have been sufficient to retard drinking in the early moments of the session.

Alternatively, neophobia may have been enhanced as a nonassociative consequence of shock exposure. Lick rates in restrained rats consistently followed an inverted $V$-shaped pattern over consecutive 5-min blocks of Test 1 when the pretreatment odor was absent (e.g., see Group RNO in the lower panel of Figure 1b). This pattern presumably reflects the time required to find the water spout and begin drinking, followed by some satiation and decreased lick rates. From this view, the low lick rates shown by inescapably shocked rats during the first $5 \mathrm{~min}$ of Test 1 could have resulted from a stress-induced deficit in exploration. If the fear of novel places was enhanced during pretreatment, inescapably shocked rats might have been slower to locate the water spout and initiate licking.

Experiment 4 was designed to assess the contribution of neophobia and handling cues to the transient suppression of drinking in inescapably shocked rats. Thirsty rats were exposed to escapable shock, yoked inescapable shock, or restraint in wheel-turn chambers containing the odor of previously shocked and restrained conspecifics. Lick-suppression tests were conducted 22 and $48 \mathrm{~h}$ later. An attempt was made to amplify any initial neophobic reaction to the drinking chambers by presenting novel peppermint odor to half of the rats in each pretreatment condition. No odor was presented to the remaining subjects. The rationale was that neophobia should extinguish more slowly when the complexity of the test context or the salience of its features are increased. Thus, if the transient suppression of drinking by INO rats in the earlier experiments stemmed from a stress-induced change in neophobia, the addition of a novel odor to the test context should exaggerate and prolong that effect.

An attempt was made to minimize the potential contribution of transportation and handling cues by making these stimuli as different as possible in each experimental phase: the rats were transported to the pretreatment session in their home cages by a female investigator; a male investigator carried the rats to the tests in unique holding cages.

\section{Method}

Subjects and Apparatus. Forty-eight male albino rats, weighing 310-341 g, were obtained from Charles River Co. and housed as in Experiment 1. Pretreatment occurred in three wheel-tum chambers identical to those described in Experiment 2, except that they were not equipped for the delivery and removal of artificial odors. These chambers were not cleaned at any point during the experiment and thus contained the odor of previously shocked and re strained conspecifics. Testing occurred in the drinking chambers described in Experiment 1.

Procedure. The rats were assigned to one of six groups of 8 rats each on the basis of weight and were adapted to the schedule of restricted water access described in Experiment 1B. Immediately after the drinking session on Day 5, two groups were exposed to escapable shock, two groups were exposed to yoked inescapable shock, and two groups were restrained in the wheel-turn chambers as in Experiment 2. However, an artificial odor was not presented 
to any group during pretreatment. All rats received an additional 15-min access to water in their home cages immediately after pretreatment.

Lick-suppression tests were conducted 22 and $48 \mathrm{~h}$ later. The drinking chambers were cleaned before each rat was tested, as in the previous experiments. Novel peppermint odor was present during testing for one group from each pretreatment condition (Groups EO, YO, and RO); no artificial odor was present for the remaining groups (ENO, YNO, and RNO). All rats received an additional 30-min access to water immediately after the first test session to compensate for differential ingestion during the session.

\section{Results and Discussion}

All rats in Groups EO and ENO learned to turn the wheel to escape shock during pretreatment. Escape latencies decreased across blocks of 10 trials and were comparable in both groups. A mixed-design ANOVA (group $X$ trial block) yielded a significant main effect of trial block $[F(7,98)=3.32, p<.01]$; however, neither the main effect of group nor the group $\times$ trial block interaction was statistically significant. Thus, Groups EO, YO, ENO, and YNO received statistically equivalent amounts of shock during pretreatment.

Overall and local lick rates in each test session are shown in Figure 4. Differences in drinking were evident only on the first test session. Overall lick rates were equivalent in the no-odor groups (ENO, YNO, and RNO), regardless of pretreatment shock condition. The presence

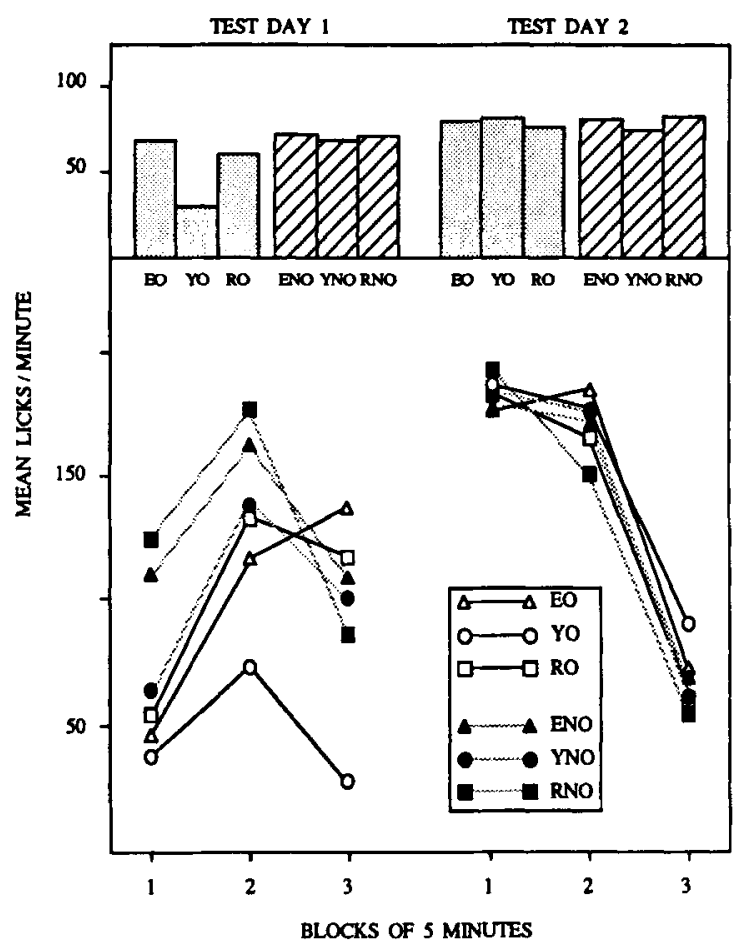

Figure 4. Mean overall (upper panel) and local (lower panel) lick rates for groups of rats exposed to escapable shock (E), yoked inescapable shock $(Y)$, or restraint $(R)$ in the presence of the odor of stressed conspecifics. Rats were tested for lick suppression in either the presence (Groups EO, YO, and RO) or the absence (Groups ENO, YNO, and RNO) of novel peppermint odor 22 and $48 \mathrm{~h}$ later. of the novel peppermint odor produced a slight reduction in overall drinking relative to no-odor levels in rats preexposed to escapable shock (EO) or restraint (RO). By contrast, drinking in Group YO was suppressed relative to all other groups during the first test session, but recovered to normal levels by the second test.

An ANOVA for randomized factors (pretreatment $x$ test odor) on overall lick rates in Test 1 yielded a significant main effect of test odor $[F(1,42)=4.29, p<.043]$ and a marginally significant main effect of pretreatment $[F(2,42)=2.98, p<.07]$. Newman-Keuls comparisons $(\alpha=.05)$ indicated that overall drinking in Group YO was significantly suppressed relative to Groups EO, ENO, YNO, and RNO. No other contrasts were statistically significant.

The local drinking patterns shown in the lower panel of Figure 4 suggest that the odor manipulation had its greatest effect early in the first test session. Whereas the presence of the novel odor generally suppressed drinking in all groups during the first 5 min of Test 1, only Group YO continued to show substantially suppressed rates during the second and third 5-min blocks of the session. A mixed-design ANOVA (group $\times$ time block) on Test 1 local rates yielded significant main effects of group $[F(5,42)=3.93, p<.01]$ and block $[F(2,84)=$ $13.20, p<.001]$. The interaction between variables was not statistically significant. Newman-Keuls comparisons $(\alpha=.05)$ indicated that Group YO drank significantly less overall during the first 15 min of Test 1 than did Groups EO, RO, ENO, YNO, and RNO, which did not differ from one another. A similar ANOVA computed on Test 2 drinking yielded a significant main effect of time block $[F(2,84)=28.06, p<.001]$, indicating that drinking decreased over time. However, neither the main effect of group nor the interaction between variables was statistically significant.

These data suggest that suppressed drinking in inescapably shocked rats in the previous experiments was not entirely the result of conditioning or associative transfer. A transient suppression of drinking was again observed for inescapably shocked rats tested in a no-odor condition. Because an associative contribution of transportation and handling cues was explicitly minimized in this experiment, this effect is not explainable in terms of the conditioning of such incidental stimuli.

The addition of a salient novel odor to the test context substantially increased the level of lick suppression in inescapably shocked rats. Overall lick rates were significantly below the levels obtained for escapably shocked rats and restrained controls. Although the novel odor generally suppressed drinking in the first minutes of Test 1 in all groups, the degree of retardation was disproportionately greater in inescapably shocked rats.

These data strongly support the idea that neophobia is enhanced as a nonassociative component of inescapable shock pretreatment. If the rats in this condition had difficulty habituating to the salient features of an environment (cf. Minor, Pelleymounter, \& Maier, 1988), any 
initial neophobic reaction should have been augmented by adding complexity or saliency to the test context. The resulting hesitancy to explore the chamber or approach the source of the novel odor would have reduced the opportunity to engage in drinking early in the session.

A comparison of the present results with those of Experiment 2 suggests that the neophobic reaction is weaker and more transient than conditioned suppression to the pretreatment odor. When the peppermint odor was associated with inescapable shock during pretreatment in Experiment 2, its presence during testing resulted in substantial lick suppression on both test days. By contrast, when peppermint occurred as a novel stimulus in the present experiment, drinking was reduced in inescapably shocked rats only during the first test session. No evidence of differential suppression was obtained on the second test. Because the test procedures were identical in these experiments, these different outcomes suggest that the effect of peppermint odor in Experiment 2 was due to prior conditioning with inescapable shock. Moreover, the difference in the magnitude of suppression in the two experiments provides some evidence that each effect is governed by a different process.

\section{EXPERIMENT 5}

Experiment 5 was designed to determine the recovery time course for enhanced neophobia following inescapable shock. Nonassociative consequences of inescapable shock (e.g., norepinephrine depletion) usually dissipate within $72 \mathrm{~h}$ of the original stress session (Weiss et al., 1981). Thus, enhanced neophobia should show comparable recovery, if it is indeed mediated by a nonassociative process. Alternatively, if this effect is associatively mediated, then the reaction should be more long-lived, as was the conditioned response to an odor associated with inescapable shock in Experiment 3.

Thirsty rats were exposed to either inescapable tailshocks or simple restraint in tubes containing the odor of previously stressed conspecifics. Lick-suppression tests were conducted either 22 or $72 \mathrm{~h}$ later for independent groups representing each pretreatment condition. Testing occurred in either the presence or the absence of novel peppermint odor.

\section{Method}

Subjects and Apparatus. Sixty-four male albino rats, weighing 287-324 g, were obtained from Charles River Co. and housed as in Experiment 1. Pretreatment occurred in restraining tubes identical to those described in Experiment 1, except that they were not equipped for the delivery of artificial odors. The tubes were not cleaned at any point during the experiment and thus contained the odor of previously shocked and restrained conspecifics. Licksuppression tests were conducted in the drinking chambers.

Procedure. The rats were assigned to one of eight groups of 8 rats each on the basis of weight and were adapted to the schedule of restricted water access. Immediately after the drinking session on Day 5, four groups of rats were exposed to 80 5-sec inescapable tailshocks, and four groups were restrained in tubes for an equivalent amount of time, as in Experiment 1B. No artificial odor was pre- sented to any group during pretreatment. All rats received an additional 15-min access to water immediately after the stress session.

Two groups from each pretreatment condition received a $30-\mathrm{min}$ lick-suppression test $22 \mathrm{~h}$ after pretreatment. Novel peppermint odor was present during testing for one shocked (IO-22) and one restrained (RO-22) group; no odor was present to the other inescapably shocked (INO-22) and restrained (RNO-22) groups. The remaining rats received 30 -min access to water in their home cages on Days 6 and 7. A 30-min lick-suppression test was conducted on Day $8,72 \mathrm{~h}$ after pretreatment. Novel peppermint odor was present during testing for one inescapably shocked (IO-72) and one restrained (RO-72) group; no odor was presented to the other shocked (INO-72) and restrained (RNO-72) groups.

\section{Results and Discussion}

Figure 5 shows the local lick rates in the groups tested 22 and $72 \mathrm{~h}$ after pretreatment. The results of the $22-\mathrm{h}$ test replicate the basic finding of the previous experiment. Although the inescapably shocked rats tested in the absence of peppermint odor (Group INO) were slow to initiate drinking, sustained suppression occurred only for the inescapably shocked rats tested in the presence of the novel odor (Group IO). By contrast, the novel odor did not differentially influence drinking among the preshocked and restrained rats (Groups IO-72 and RO-72, respectively) tested $72 \mathrm{~h}$ after pretreatment, although a slight suppressive effect of the odor was evident relative to each group's no-odor counterpart (Groups INO-72 and RNO-72).

A mixed-design ANOVA (group $\times$ time block) of drinking by the groups tested $22 \mathrm{~h}$ after pretreatment yielded significant main effects of group $[F(3,28)=4.79$, $p<.01]$ and time block $[F(2,56)=13.56, p<.001]$, and a significant group $\times$ time block interaction $[F(6,56)=$ $2.62, p<.03$ ]. Newman-Keuls comparisons $(\alpha=.05)$ of overall drinking indicated that Group IO drank significantly less during the first 15 min of the session than did Groups INO, RNO, and RO, which did not differ from

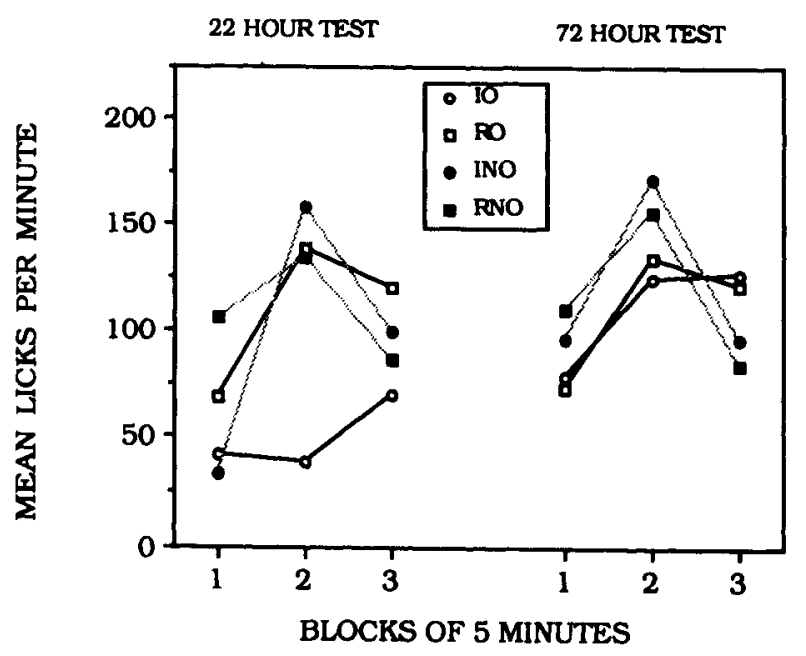

Figure 5. Mean lick rates in blocks of $5 \mathrm{~min}$ for rats exposed to inescapable shock (I) or restraint $(R)$ in the presence of conspecific stress odors and then tested for lick suppression 22 or 72 h later in either the presence (Groups IO and RO) or the absence (Groups INO and RNO) of novel peppermint odor. 
one another. Interaction contrasts (Newman-Keuls, $\alpha=$ .01 ) indicated that Groups IO and INO drank at a significantly lower rate than Group RNO during the first $5 \mathrm{~min}$ of the session; Group RO did not differ significantly from Groups IO and INO. However, during the second 5-min period, drinking was equivalent among Groups RO, INO, and RNO. All three groups drank at a significantly higher rate than Group IO. Lick rates were statistically equivalent among groups during the third $5 \mathrm{~min}$ of the session. In contrast to these findings, a mixed-design ANOVA of the data from the 72 -h test yielded only a significant main effect of time block $[F(2,56)=17.68, p<.001]$. Neither the main effect of group nor the group $\times$ time block interaction was statistically significant.

These data indicate that enhanced neophobia following inescapable shock dissipates within $72 \mathrm{~h}$ of the stress session. Transient suppression of drinking at the beginning of the test session, and the augmentation of this effect in the presence of a novel odor, were evident in inescapably shocked rats $22 \mathrm{~h}$ after pretreatment. Both effects were absent from the 72 -h test. Thus, whereas conditioned suppression to the pretreatment odor was retained for at least $72 \mathrm{~h}$ (Experiment 3), the neophobic reaction dissipated rather rapidly. A shorter recovery time is consistent with the idea that an exaggerated fear of novel places is a nonassociative consequence of uncontrollable stressors.

The loss of enhanced neophobia over the $72 \mathrm{~h}$ following inescapable shock may have influenced the time course for retention of conditioned suppression in Experiment 3 . Conditioned and unconditioned sources of fear probably combined in some manner to determine overall lick suppression in the 10 rats during the 22 -h test. However, evidence of an unconditioned component of test drinking was absent $72 \mathrm{~h}$ after pretreatment in both Experiment 3 and the present experiment. Thus, the slight loss of suppression to the pretreatment odor at the longer retention interval in Experiment 3 may not have resulted from a decrease in the strength of the odor-shock association; instead, it may have reflected recovery from neophobia and elimination of the nonassociative component of overall lick suppression.

\section{EXPERIMENT 6}

This final experiment was designed to assess the potential interaction between conditioned and unconditioned fear during transfer testing. The available data suggest that the unconditioned reaction is relatively weak and transient in comparison to the conditioned suppression associated with a pretreatment odor. However, the actual contribution of neophobia to test performance may depend upon how these two sources of fear interact.

If conditioned fear and neophobia simply summate, then the contribution of neophobia to helplessness effects probably is quite small. Alternatively, these effects could act synergistically. For instance, some initial neophobia may be necessary for the conditioned properties of the pretreatment odor to be expressed. The presence of a conditioned danger signal (e.g., the pretreatment odor) in an un- familiar environment could serve to enhance or maintain any initial neophobic reaction.

The latter hypothesis could account for the failure of the pretreatment odor to differentially suppress drinking in Experiment 1A. Because rats were familiarized with the drinking chambers during baseline sessions in that experiment, the test context probably did not elicit a neophobic reaction at the time of transfer testing. The conditioned properties of the pretreatment odor were not expressed under these test conditions. However, differential suppression of drinking was obtained in Experiment $1 \mathrm{~B}$ when the odor was presented in a novel surrounding. Although this difference in procedure and outcome suggests that novelty of the test context may have an important influence on transfer testing, these experiments also differed in terms of the motivational significance of the drinking chambers at the time of testing. Prior association of the test context with water availability could have been responsible for the absence of an effect in Experiment 1A.

In Experiment 6, the effect of test-context novelty on the expression of conditioned fear during transfer testing was directly assessed. Rats were initially habituated to the test apparatus over 5 consecutive days. Unlike Experiment $1 \mathrm{~A}$, however, water was not available in the drinking chambers during these sessions. Other rats were habituated to holding cages, but were not exposed to the test chambers. Rats from each habituation condition were then exposed to either inescapable tailshocks or restraint in tubes odorized by peppermint extract. Lick-suppression tests were conducted 22 and 48 h later. The pretreatment odor was present for all groups. If neophobia is necessary for the conditioned properties of the pretreatment odor to be expressed in a transfer test, then initial familiarization with the test apparatus should markedly reduce the level of lick suppression in shocked rats. Alternatively, habituation sessions should have no impact on test performance if repeated opportunities to drink in the chamber prior to testing were responsible for the outcome of Experiment 1A.

\section{Method}

Subjects and Apparatus. Thirty-two male albino rats, weighing 295-340 g, were obtained from Charles River Co. and housed as in Experiment 1. The apparatus was the same as in Experiment 1.

Procedure. The rats were assigned to one of four groups of 8 rats each on the basis of weight and were adapted to the drinking schedule described in Experiment 1B. Two groups were familiarized with the test chamber over the 5 days of baseline drinking: these rats were placed in the test chambers for $30 \mathrm{~min}$ at nonspecific times following each home-cage drinking session. Access to the water spout in the drinking chambers was blocked by covering the aperture in the main chamber with an aluminum plate. The test chambers were thoroughly cleaned before each session for each rat; no odors were presented. The rats in the other two groups were habituated to carrying cages during these sessions, but were not exposed to the test chamber.

Immediately after the last habituation session, one group from each habituation condition was exposed to 805 -sec inescapable tail shocks in restraining tubes as in Experiment 1B. The other two groups were restrained in tubes for an equivalent amount of time, but received no shocks. Peppermint was the pretreatment odor for all groups. All rats received an additional 15-min access to water 
in their home cages immediately after the stress session. Thus, four groups were created by this combination of conditions: rats familiar with the test context and exposed to either inescapable shock (Group IF) or restraint (Group RF) during pretreatment, and rats for which the test context was novel and exposed to shock (Group IN) or restraint (Group RN).

Lick-suppression tests were administered 22 and $48 \mathrm{~h}$ after pretreatment. The pretreatment odor was present during each test for all groups. All rats received an additional 30-min access to water in their home cages immediately after the first test.

\section{Results and Discussion}

Overall lick rates for each group are shown in Figure 6 for the two test sessions. Drinking was suppressed in shocked rats tested in the novel context (Group IN) relative to the appropriate restrained control group (RN) during the first test. Comparable lick rates occurred in shocked (IF) and restrained (RF) groups when the test context was familiar. However, both groups showed lower levels of drinking than Group RN. The relative standing among groups shifted during Test 2 . Whereas drinking in Group IN remained suppressed relative to all other groups, drinking increased in Groups IF and RF to a level comparable to that in Group RN. Thus, the pretreatment odor failed to differentially suppress drinking in inescapably shocked rats when the test context was familiar.

A mixed-design ANOVA (habituation condition $\times$ pretreatment condition $\times$ test day) yielded significant main effects of pretreatment $[F(1,28)=16.51, p<.001]$ and test day $[F(1,28)=11.95, p<.002]$. The habituation $\times$ pretreatment $[F(1,28)=8.10, p<.009]$ and habituation $\times$ test day interactions $[F(1,28)=3.98, p<.05]$ also were statistically significant. Newman-Keuls comparisons $(\alpha=.05)$ of overall drinking during the first test session indicated that lick rates were higher in Group RN than in all other groups. Drinking was equivalent in Groups RF and IF; both of these groups drank at a higher overall rate than Group IN. By contrast, overall drinking was equivalent among Groups RN, RF, and IF during the second test session. All three groups drank at a higher rate than Group IN.

These data indicate that the pretreatment odor does not differentially suppress drinking in inescapably shocked rats when the test context is familiar at the time of transfer testing. Unlike Experiment 1A, the similarity between Groups IF and RF cannot be attributed to competition from strong appetitive motivation, but rather must have resulted from initial habituation to the test apparatus.

The pretreatment odor resulted in substantial, but equivalent, lick suppression in Groups IF and RF during the first test session for reasons that are not altogether clear. As discussed below, factors other than the associative value of the pretreatment odor may have contributed to reduced drinking in these groups in Test 1 . Nonetheless, the results of the second session clearly indicate that initial habituation to the test context drastically diminished the fear-inducing properties of an odor associated with inescapable shock. Whereas lick rates remained suppressed in the IN rats during the second test session, ingestion by the IF rats was equal to control levels. Thus, some neophobia of the test context is apparently necessary for the conditioned properties of an odor associated with inescapable shock to be fully expressed.

\section{GENERAL DISCUSSION}

These experiments were performed to examine the conditioning and transsituational transfer of fear following escapable and inescapable shock. Two sources of fear combined to suppress the test drinking of inescapably shocked rats. An artificial odor presented during pretreatment became a strong conditioned cue for inescapable shock and mediated the associative transfer of fear to a

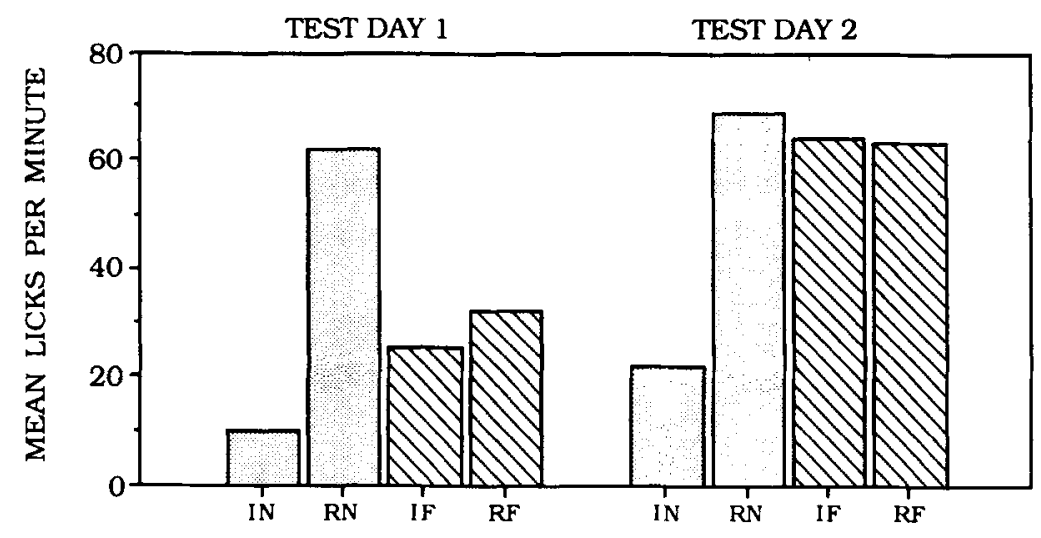

Figure 6. Mean lick rates in each of two 30-min test sessions for the groups in Experiment 6 . Thirsty rats were either familiarized (F) with the test chambers in the absence of the water spout over five consecutive 30-min sessions, or were not exposed to the test chambers $(N)$ before pretreatment with inescapable shock (I) or restraint $(R)$ in the presence of peppermint odor. Lick-suppression tests were conducted 22 and $48 \mathrm{~h}$ later in either the familiar (Groups IF and RF) or the novel (Groups IN and RN) apparatus. The pretreatment odor was present during testing for all groups. 
test conducted in a different apparatus. Substantial lick suppression occurred in inescapably shocked rats only when the pretreatment odor was present during testing (Experiments $1 \mathrm{~B}, 2$, and 3 ). However, inescapably shocked rats tested in the absence of the pretreatment odor were consistently slower than restrained controls to initiate drinking during the first test session (Experiments 1B-6). This transient suppression is not easily attributed to the conditioning of incidental stimuli (Experiment 4) and suggests that neophobia - the fear of novel places-was enhanced as a nonassociative consequence of inescapable shock. Consistent with this possibility is the finding that the presence of a novel odor in the test apparatus, a manipulation intended to increase the complexity and saliency of the test environment, differentially enhanced the transient effects of neophobia in inescapably shocked rats.

The odor-shock association established during pretreatment was retained for at least $72 \mathrm{~h}$ (Experiment 3). Because many of the behavioral and physiological effects of inescapable shock dissipate within this time interval (Maier et al., 1980; Seligman et al., 1975), forgetting cannot be solely responsible for time-dependent variations in helplessness. Thus, even though the presence of the pretreatment odor in the test apparatus is a necessary condition for several measures of helplessness to be observed $24 \mathrm{~h}$ after inescapable shock (Coen, 1985; Minor \& LoLordo, 1984; Williams, 1987), some other factor must contribute to the production of and recovery from helplessness.

Unlike conditioned fear, the ability of a novel odor to differentially enhance neophobia dissipated within $72 \mathrm{~h}$ of exposure to inescapable shock (Experiment 5). This recovery interval is similar to that obtained for the nonassociative neurochemical effects of inescapable shock (Weiss et al., 1981) and is consistent with the idea that enhanced neophobia occurred as a nonassociative consequence of the stress session. Indeed, enhanced neophobia may have been a product of the alteration in brain catecholamine levels. Among other changes, exposure to inescapable shock depletes norepinephrine in the locus coeruleus and the forebrain projection regions of the ascending dorsal tegmental bundle (e.g., Anisman \& Zacharko, 1986; Minor et al., 1988; Weiss et al., 1981). This stress-induced depletion may serve as a functional lesion, albeit a reversible one, of the ascending noradrenergic pathway (cf. Gray, 1982; Minor et al., 1988). In this regard, chemical and electrolytic lesions of these neurons selectively enhance behavioral responsivity to novelty (Britton, Ksir, Thatcher-Britton, Young, \& Koob, 1984). Lesioned rats are more hesitant to eat in a novel apparatus than are sham controls under these conditions, but feed normally in a familiar one. Such data suggest that the hesitancy of inescapably shocked rats to drink in a novel test chamber in the present study was a behavioral reflection of the stress-induced imbalance in neurotransmitter concentrations associated with inescapable shock. Because stress-induced changes in neurotransmission generally recover within $72 \mathrm{~h}$ of the original shock session (e.g., Weiss et al., 1981), inescapably shocked rats would not have been expected to show enhanced neophobia $72 \mathrm{~h}$ poststress if this were the case.

Conditioned fear and neophobia combined in a nonadditive manner to suppress test drinking in inescapably shocked rats. Some neophobia of the test context was necessary before the conditioned properties of the pretreatment odor were fully expressed. When subjects were familiarized with the test apparatus prior to transfer testing (Experiments $1 \mathrm{~A}$ and 6), an odor associated with inescapable shock failed to differentially suppress drinking.

Several factors may have contributed to this absence of differential suppression. Initial familiarization with the drinking chambers obviously eliminated the contribution of neophobia to test performance. More importantly, conditional stimuli appear to have ambiguous signal value when tested outside the original conditioning context (cf. Bouton \& Bolles, 1979), and several processes could have worked against the expression of conditioned fear when the odor was tested in a familiar apparatus. For instance, inescapably shocked rats may have learned that the drinking chambers were "safe" during the habituation sessions, thereby reducing the odor's excitatory potential during transfer testing. A more elaborate possibility is suggested by Barbaree and Weisman's (1975) finding that a freeoperant avoidance response established with gridshock was not altered by the presentation of a tone signaling tailshock, and vice versa. Responding was enhanced only when the tone signaled the same mode of shock delivery that maintained the avoidance baseline. In this regard, familiarization training may have enhanced the discrimination of critical stimulus features in the pretreatment and test apparatus. Because the drinking chambers lacked the stimuli associated with tailshock, fear of the pretreatment odor may not have transferred. Yet another alternative is that the pretreatment odor was perceived as being separate from the remaining elements of the test context by subjects receiving initial familiarization sessions. The enhanced "figure-ground" contrast between the odor and other situational elements may have hastened the extinction of any conditioned aversive properties of the odor (cf. Lubow, Rifkin, \& Alek, 1976). This type of perceptual contrast could also account for initial suppression of drinking in restrained controls in this test condition (Experiments $1 \mathrm{~A}$ and 6 ). Reduced drinking by control (or shocked) rats may reflect greater processing of a stimulus (i.e., the odor) that was not associated with the test context in earlier sessions.

These processes could not have influenced drinking when the drinking chamber was novel at the time of transfer testing. Conditioned fear and neophobia may have worked synergistically in this condition to maximize lick suppression in inescapably shocked rats. When the test context was novel, the rats had no basis for assessing the relative safety of the situation or its ability to support the type of shock delivered during pretreatment. Although the pretreatment odor probably was a salient feature of the test context, it should not have been perceived as uniquely distinct from other contextual elements. Without such fac- 
tors to mitigate the expression of fear or hasten its extinction, maximum conditioned suppression should have resulted from the presence of the pretreatment odor. Moreover, the presence of a conditioned danger signal in an otherwise unfamiliar environment may have enhanced and maintained any initial wariness of the novel chamber, thus maximizing the nonassociative contribution to suppressed drinking.

These findings concerning inescapable shock support a two-factor interpretation of helplessness based on fear or anxiety (Minor \& LoLordo, 1984; Weiss et al., 1982). Behavioral evidence of an associative and a nonassociative effect of inescapable shock was obtained during transfer testing. The associative component, conditioned fear, was retained for at least $72 \mathrm{~h}$, suggesting that the recovery from helplessness effects within this interval is not governed by an associative process. Enhanced neophobia presumably occurred as a reflection of the nonassociative effects of inescapable shock on neurochemical concentrations and neurotransmission. These two sources of fear interacted in a nonadditive manner to determine the total level of fear during transfer testing $24 \mathrm{~h}$ after pretreatment. The ability of the pretreatment odor to suppress drinking $24 \mathrm{~h}$ after inescapable shock was dramatically reduced when expression of the nonassociative component was eliminated by initial familiarization with the test context. Because enhanced neophobia dissipated within $72 \mathrm{~h}$ of the initial stress session, these results suggest that the dissipation of helplessness over time is governed by recovery from the nonassociative effects of inescapable shock. Thus, as Weiss et al. (1981) predicted, critical apparatus cues retain the ability to elicit fear over long intervals, but lose the ability to reinstate the neural imbalance originally produced by inescapable shock and its nonassociative contribution to test fear and performance when testing occurs at relatively long postshock times.

The present experiments also provide additional evidence that escapable shock is less fear-provoking than inescapable shock. The presentation of an odor associated with escapable shock produced less initial conditioned suppression during testing, which extinguished more rapidly, than did an odor associated with inescapable shock (Experiment 2). Pretreatment with escapable shock also failed to enhance neophobia of the test context (Experiment 4). These outcomes suggest that inescapably shocked rats not only experience more fear during pretreatment, but also begin the test task more afraid than do escapably shocked rats. Heightened fear at the time of testing is likely to alter the selection and processing of task-relevant stimuli (Minor et al., 1984; Minor et al., 1988), reduce the capacity of endogenous vegetative processes to cope with the stressor (Anisman \& Zacharko, 1986; Dess, Minor, \& Brewer, 1989; Haracz et al., 1988; Weiss \& Simson, 1985), and result in the perseveration of innately prepared or welltrained motor programs (Anisman \& Zacharko, 1986).

Although the present data do not specify a mechanism for the stress-reducing potential of escapable shock, several recent observations suggest that fear is reduced as a Pavlovian consequence of instrumental responding.
Exposure to unsignaled, inescapable shock can be viewed as a low-information condition in which subjects are unable to discriminate between periods of danger and safety, and remain chronically afraid as a result (Mowrer \& Viek, 1948; Seligman, 1968). During escapable shock, on the other hand, stimuli generated by the act of escaping may become signals for shock termination (Minor, Dess, et al., in press; Minor, Trauner, Lee, \& Dess, 1990) and a shock-free period (Jackson \& Minor, 1988; Mineka et al., 1984; Rosellini, DeCola, \& Warren, 1986). These putative predictive features of an escape response should be modeled, respectively, by Pavlovian cessation and backward conditioning. Both procedures yield potent conditioned inhibitors of fear that either directly mitigate the unconditioned reaction to shock or reduce fear during the intershock interval (Moscovitch, 1972; Moscovitch \& LoLordo, 1968; Segundo, Galeano, Sommer-Smith, \& Roig, 1961). Importantly, exteroceptive stimuli presented in cessation and backward relations with inescapable shock can prevent later shuttle-escape deficits and other measures of distress and helplessness. The level of protection afforded by such signals under various conditions is strongly correlated with their fear-inhibiting potential (see Minor et al., in press, and Warren, Rosellini, \& Maier, in press, for recent reviews). Thus, escapable shock may be less fear-provoking than inescapable shock because it yields predictive stimuli with fear-inhibiting properties.

\section{REFERENCES}

Anderson, D. C., Crowell, C. R., Cunningham, C. L., \& LUPO, J. V. (1979). Behavior during shock exposure as a determinant of subsequent interference with shuttle box escape-avoidance learning in the rat. Journal of Experimental Psychology: Animal Behavior Processes, 5, 243-257.

Anisman, H., ZACHARKo, R. M. (1986). Behavioral and neurochemical consequences associated with stressors. In D. D. Kelly (Ed.), Stress-induced analgesia (Vol. 467, pp. 205-225). New York: Annals of the New York Academy of Sciences.

Barbaree, H. E., Weisman, R. G. (1975). On the failure of transfer of control from separately conducted Pavlovian conditioning to free-operant avoidance conditioning in rats. Leaming \& Motivation, 6, 498-511.

Bouton, M. E., \& Bolles, R. C. (1979). Role of conditioned contextual stimuli in the reinstatement of extinguished fear. Journal of Ex perimental Psychology: Animal Behavior Processes, 5, 368-378.

Bracewell, R. J., BlaCk, A. H. (1974). The effects of restraint and noncontingent pre-shock on subsequent escape learning in the rat. Learning \& Motivation, 5, 53-69.

Brennan, J. F., \& Riccio, D. C. (1975). Stimulus generalization of fear in rats following aversively motivated instrumental or Pavlovian training. Journal of Comparative \& Physiological Psychology, 88, 570-579.

Brimer, C. J., K KAMIN, L. J. (1963). Fear of the CS in avoidance training and fear from the sense of helplessness. Canadian Journal of Psychology, 17, 188-193.

Britton, D. R., Ksir, C., Thatcher-Britton, K., Young, D., \& КоОв, G. F. (1984). Brain norepinephrine depleting lesions selectively enhance behavioral responsiveness to novelty. Physiology \& Behavior, 33, 473-478.

Brown, R. J. (1979). Mammalian social odors: A critical review. In J. S. Rosenblatt, R. A. Hinde, C. Beer, \& M. Bushnel (Eds.), Advances in the study of behavior (Vol. 10, pp. 103-160). New York: Academic Press.

COEN, D. J. (1985). Context and pain perception: Stress-induced analgesia as a function of similarity of odor and apparatus cues between 
stress analgesia assessment environments. Unpublished master's thesis, University of Alberta, Edmonton.

Desiderato, O., \& Newman, A. (1971). Conditioned suppression produced in rats by tones paired with escapable and inescapable shock. Journal of Comparative \& Physiological Psychology, 77, 427-431.

Dess, N. K., Chapman, C. D., Minor, T. R. (1988). Inescapable shock increases finickiness about drinking quinine-adulterated water in rats. Learning \& Motivation, 19, 408-424.

Dess, N. K., Minor, T. R., * Brewer, J. C. (1989). Suppression of feeding and body weight by inescapable shock: Modulation by food palatability, stress reinstatement, and controllability. Physiology \& Behavior, 45, 975-983.

Glazer, H. I., Weiss, J. M. (1976). Long-term interference effect: An alternative to "leamed heiplessness." Joumal of Experimental Psychology: Animal Behavior Processes, 2, 201-213.

GraY, J. A. (1982). The neuropsychology of anxiety. Oxford: Oxford University Press.

Haracz, J. L., Minor, T. R., Wilkins, J. N., Zimmermann, E. G. (1988). Learned helplessness: An experimental model of the DST in rats. Biological Psychiatry, 23, 388-396.

Hoffman, H. S., Fleshler, M., \& Jensen, P. (1963). Stimulus aspects of aversive controls: The retention of conditioned suppression. Journal of the Experimental Analysis of Behavior, 6, 575-583.

JACKSON, R. L., MINOR, T. R. (1988). Effects of signaling inescapable shock on subsequent escape learning: Implications for theories of coping and "learned helplessness." Joumal of Experimental Psychology: Animal Behavior Processes, 14, 390-400.

KING, M. G. (1969). Stimulus generalization of conditioned fear in rats over time. Journal of Comparative \& Physiological Psychology, 69, $590-600$.

Lubow, R. E., Rifkin, B., \& Alek, M. (1976). The context effect: The relationship between stimulus preexposure and environmental preexposure determines subsequent learning. Journal of Experimental Psychology: Animal Behavior Processes, 2, 38-47.

Mater, S. F., CoON, D. J., MCDAniel, M. A., JACKson, R. L., GraU, J. (1980). The time course for learned helplessness, inactivity, and nociceptive deficits in rats. Learning \& Motivation, 10, 467-487.

Maier, S. F., \& Seligman, M. E. P. (1976). Learned helplessness: Theory and evidence. Joumal of Experimental Psychology: General, 105, 3-46.

MineKa, S., Cook, M., \& Miller, S. (1984). Fear conditioned with escapable and inescapable shock: Effects of a feedback stimulus. Journal of Experimental Psychology: Animal Behavior Processes, 10, 307-324.

Minor, T. R., Dess, N. K., \& Overmier, J. B. (in press). Inverting the traditional view of "learned helplessness": A reinterpretation in terms of anxiety and modulator operations. In M. R. Denny (Ed.), Aversive events and behavior. Hillsdale, NJ: Erlbaum.

MinoR, T. R., JACKSON, R. L., MAIER, S. F. (1984). Effects of taskirrelevant cues and reinforcement delay on choice escape learning following inescapable shock: Evidence for a deficit in selective attention. Joumal of Experimental Psychology: Animal Behavior Processes, 10, 543-556.

MinOR, T. R., \& LoLordo, V. M. (1984). Escape deficits following inescapable shock: The role of contextual odor. Joumal of Experimental Psychology: Animal Behavior Processes, 10, 168-181.

Minor, T. R., Pelleymounter, M. A., \& MAier, S. F. (1988). Uncontrollable shock, forebrain norepinephrine, and stimulus selection during choice-escape learning. Psychobiology, 16, 135-145.

Minor, T. R., Trauner, M. A., Lee, C. Y., Dess, N. K. (1990). Modeling the signal features of an escape response: Effects of cessation conditioning in the "learned helplessness" paradigm. Journal of Experimental Psychology: Animal Behavior Processes, 16, 123-136.

MorRIs, R. G. M. (1974). Pavlovian conditioned inhibition of fear during shuttlebox avoidance behavior. Learning \& Motivation, 5, 424-447.

Moscovitch, A. (1972). Pavlovian cessation conditioning. Unpublished doctoral dissertation, University of Pennsylvania, Philadelphia.

Moscovitch, A., \& LoLordo, V. M. (1968). Role of safety in the Pav- lovian backward conditioning procedure. Journal of Comparative \& Physiological Psychology, 66, 673-678.

Mowrer, O. H., \& VieK, P. (1948). An experimental analogue of fear from a sense of helplessness. Journal of Abnormal \& Social Psychology, 43, 193-200.

Osborne, F. H., Mattingly, B. A., Redmon, W. K., Osborne, J. S. (1975). Factors affecting the measurement of classically conditioned fear in rats following exposure to escapable versus inescapable signaled shock. Joumal of Experimental Psychology: Animal Behavior Processes, 1, 364-373.

PAYNE, R. (1972). Alteration of Sidman avoidance baselines by CSs paired with avoidable and unavoidable shock. Psychological Reports, 31, 291-294.

RANDICH, A., \& LoLoRDo, V. M. (1979). Associative and nonassociative theories of the UCS preexposure phenomenon: Implications for Pavlovian conditioning. Psychological Bulletin, 86, 523-548.

Rosellini, R. A., DeCola, J. P., \& Warren, D. A. (1986). The effects of feedback on contextual fear depend upon the minimum intertrial interval. Learning \& Motivation, 17, 229-242.

Segundo, J. P., Galeano, C., Sommer-Smith, J. A., \& Roig, J. A. (1961). Behavioral and EEG effects of tones reinforced by cessation of painful stimuli. In A. Fessard, R. W. Gerard, \& J. Konorski (Eds.), Brain mechanisms and learning (pp. 265-292). Oxford: Blackwell.

Seligman, M. E. P. (1968). Chronic fear produced by unpredictable electric shock. Journal of Comparative \& Physiological Psychology, 66, 402-411.

Seligman, M. E. P., Maier, S. F. (1967). Failure to escape traumatic shock. Journal of Experimental Psychology, 74, 1-9.

Seligman, M. E. P., Maier, S. F., Geer, J. (1968). The alleviation of learned helplessness in the dog. Journal of Abnormal Psychology, 73, 256-262.

Seligman, M. E. P., Rosellini, R. A., \& Kozak, M. J. (1975). Learned helplessness in the rat: Time course, immunization and reversibility. Journal of Comparative \& Physiological Psychology, 88, 542-547.

SPEAR, N. E. (1978). The processing of memories: Forgetting and retention. Hillsdale, NJ: Erlbaum.

Thomas, D. A., Riccio, D. C., \& MYer, J. S. (1977). Age of stressproduced odorants and the Kamin effect. Behavioral Biology, 20, 433-440.

WARren, D. M., Rosellini, R. A., * MaIer, S. F. (in press). Fear, feedback, and stressor controllability. In G. H. Bower (Ed.), The psychology of learning and motivation (Vol. 23). New York: Academic Press.

Weisman, R. G., \& Litner, J. S. (1972). The role of Pavlovian effects in avoidance learning. In R. A. Boakes \& M. S. Halliday (Eds.), Inhibition and learning (pp. 253-270). New York: Academic Press.

Weiss, J. M., Bailey, W. H., Goodman, P. A., Hoffman, L. J., Ambrose, M. J., Salman, S., \& Charry, J. M. (1982). A model for the neurochemical study of depression. In M. Y. Springstein \& A. Levy (Eds.), Behavioral models and the analysis of drug action (pp. 195-223). Amsterdam: Elsevier.

Weiss, J. M., Goodman, P. A., Losito, B. G., Corrugan, S., Charry, J. M., \&AILEY, W. H. (1981). Behavioral depression produced by an uncontrollable stressor: Relationship to norepinephrine, dopamine, and serotonin levels in various regions of rat brain. Brain Research Reviews, 3, 167-205.

WeIss, J. M., \& SIMSON, P. G. (1985). Neurochemical mechanisms underlying stress-induced depression. In T. Field, P. McCabe, \& N. Schneiderman (Eds.), Stress and coping (pp. 93-116). Hillsdale, NJ: Erlbaum.

WiLLiams, J. L. (1987). Influence of conspecific stress odors and shock controllability on conditioned defensive burying. Animal Learning \& Behavior, 15, 333-341.

(Manuscript received February 28, 1989; revision accepted for publication October 2, 1989.) 